\title{
Professoras de Educação Física: duas histórias, um só destino ${ }^{1}$
}

Luciano de Almeida*

Paulo Evaldo Fensterseifer ${ }^{* *}$

\begin{abstract}
Resumo: Este artigo desvela a trajetória de duas professoras de Educação Física de uma escola pública de Santo Augusto/RS que, apesar de serem formadas em diferentes momentos históricos, produzem uma prática semelhante, caracterizada pela adoção de atividades esportivas com um fim em si mesmas. Essa constatação nos leva a reconhecer a necessidade de explicitarmos as especificidades da educação escolar, em particular da Educação Física, bem como a melhor compreender a cultura escolar. A experiência da busca de compreensão das práticas pedagógicas de outros profissionais pode nos fornecer elementos para (re)significar nossas próprias ações na escola.
\end{abstract}

Palavras-chave: Ensino fundamental e médio. Prática profissional. Educação física. Fatores culturais.

\section{INTRODUÇÃO}

Parece-nos relevante, antes de iniciarmos a análise da constituição das professoras de educação física da escola e a sua relação com o contexto escolar, fazermos uma referência especial ao processo construído para chegar a esta investigação.

Nossa intenção primeira foi a de construir uma proposta de trabalho para a Educação Física Escolar em um contexto específico; para isso, buscamos constituir um grupo de estudos em uma escola da rede pública estadual de Santo Augusto/RS. Na apresentação do projeto aos professores da escola ocorreu o primeiro "desvio" no caminho traçado. A certeza inicial de desenvolver o referido projeto

\footnotetext{
${ }^{1}$ Este artigo é baseado na dissertação de mestrado defendida em julho de 2004 na Universidade Regional do Noroeste do Estado do Rio Grande do Sul e tem como título: "O contexto escolar e o profissional de educação física".

* Mestre em Educação nas Ciências pela UNIJUÍ. Professor do Curso de Educação Física da URI, Campus Santo Ângelo e Professor da Escola Estadual de Ensino Médio Santo Augusto. E-mail: lucianoedf@urisan.tche.br

** Doutor em Filosofia da Educação pela UNICAMP. Docente do Departamento de Pedagogia da UNIJUÍ. E-mail: fenster@unijui.tche.br
} 


\section{Astigor Originais}

foi obstruída pelo comportamento de oposição dos professores nos encontros realizados, o que nos levou a uma mudança de estratégia. Essa mudança justifica-se nas falas enunciadas pelos professores em nossos encontros, como: "falta de materiais", "falta de vontade dos alunos" e "isso não dá certo porque os alunos não querem nada com nada". Tais discursos são incorporados como "verdades" e acabam por justificar a atuação dos professores na escola.

Utilizamo-nos do termo "comportamento de oposição" para evitar a simplificação do conceito de resistência. Segundo Giroux (1986, p. 145), este conceito vem sendo utilizado pelos educadores "com uma dose grande de descuido teórico". Para o autor, a resistência

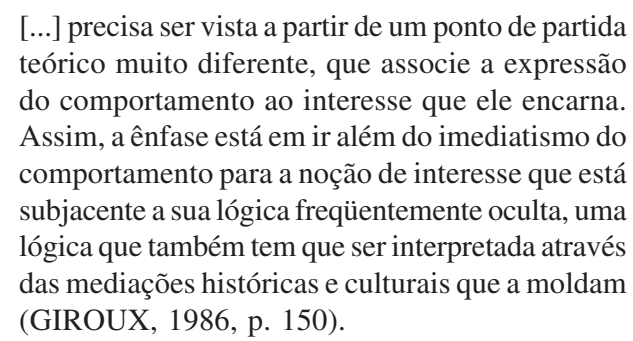

Nesse caso, é preciso analisar as práticas subjacentes aos discursos produzidos pelos professores, quando estes se opõem à criação do grupo de estudos. Para não corrermos o risco de cair num denuncismo fácil e simplificador da prática pedagógica dos professores, trilhamos um novo caminho buscando compreender como os professores desta escola elaboram esses discursos, a partir de que referenciais constituem-se profissionais de Educação Física, suas histórias, seus desejos, suas angústias e suas intenções de re-significar suas próprias ações na escola, além de analisamos o contexto em que se inserem e sua intervenção profissional.

Um fator, que merece destaque e precisa ser explicitado, diz respeito à escolha de duas professoras para a representação do grupo de Educação Física. Além da disponibilidade dessas professoras em participar das entrevistas, destacamos o fato de que, nos encontros realizados para a constituição do grupo de estudos eapresentação do projeto de pesquisa, tomamos conhecimento de que essas duas professoras fizeram/fazem parte de uma história

Movimento, Porto Alegre, v.13, n. 02, p.13-35, maio/agosto de 2007. 
constituída nessa escola. As professoras, que hoje fazem parte do quadro docente da escola, já foram professora e aluna nesta mesma instituição em que atuam.

No decorrer deste trabalho, as professoras serão identificadas como Professora A e Professora B, no intuito de preservar suas identidades. O critério estabelecido para essa escolha foi o tempo de trabalho docente como professoras de Educação Física nessa instituição, onde a professora $\mathrm{A}$ atua há mais de vinte anos e a professora $\mathrm{B}$, há pouco mais de cinco anos.

$\mathrm{Na}$ trajetória dessas professoras, analisamos o complexo processo de construção de significados a partir da interação com o outro (social), sua inserção na cultura, fazendo/sendo história. Ao analisarmos as falas dessas professoras, encontramos a criança/adolescente/mulher que internaliza/apropria-se da cultura em que se insere, compondo com seus referenciais o arcabouço a ser mobilizado em suas práticas pedagógicas. Essas professoras fazem parte de uma história desenvolvida no interior da instituição escolar, materializada nas relações professora/aluna e professora/ professora, constituindo as profissionais de uma mesma área, trilhando caminhos que se cruzam, que se enlaçam e se separam, mas que demonstram escolhas diferentes para a mesma profissão. Evidenciamos aqui a construção de uma identidade que não pode ser expressa apenas por números, mas por relações com o meio físico e social, com a cultura, com a história. Nesse sentido, é que buscamos, no diálogo com as obras consultadas, alguns referenciais que nos auxiliaram a compreender como as professoras vão se constituindo profissionais de Educação Física.

\section{ALGUNS REFERENCIAIS PARA COMPREENDER A CONSTITUIÇÃO DAS PROFESSORAS DA ESCOLA}

Com base em Vigotski (2002), podemos afirmar que, desde que nascemos, nossos gestos são significados pelo outro. Um exemplo clássico para tal afirmação apresenta-se no simples gesto de apontar de uma criança, que em princípio é uma tentativa mal sucedida de pegar algo (objeto) que está além de seu alcance. Na intervenção da

Movimento, Porto Alegre, v.13, n. 02, p.13-35, maio/agosto de 2007. 


\section{Artifor Originais}

mãe, este simples movimento de agarrar e pegar, transforma-se em um ato de apontar; portanto, significado pelo adulto (outro).

Inseridos em um determinado contexto, vamos nos apropriando da cultura a partir das interações sociais. No exemplo dado, percebemos a importância do outro em nossa constituição. Somos sujeitos históricos, projetos humanos em construção dependentes dos outros para nos tornarmos humanos. Segundo Kant (2002), a educação consiste, basicamente, em homens que educam homens em homens. Não há como fugir da premissa de que marcamos e somos marcados, transformamos e somos transformados pela cultura, na interação com o meio físico e social.

Através das relações com o outro, os indivíduos vão internalizando/ apropriando-se da cultura em permanentes atos de significação. Amparados nas obras de Vigotski, podemos caracterizar o que o autor chama de processo de internalização, justificando uma série de transformações:

Um processo interpessoal é transformado num processo intrapessoal. Todas as funções no desenvolvimento da criança aparecem duas vezes: primeiro, no nível social, e, depois, no nível individual; primeiro, entre pessoas (interpsicológica), e, depois, no interior da criança (intrapsicológica). Isso se aplica igualmente para a atenção voluntária, para a memória lógica e para a formação de conceitos. Todas as funções superiores originamse das relações reais entre indivíduos humanos (VIGOTSKI, 2002, p. 75).

A partir das palavras do autor, é possível afirmar que, nas diferentes relações que são estabelecidas com o outro (social), os sujeitos constituem sua individualidade. Ao internalizar signos (palavras), produz-se referenciais "próprios" para o agir, o pensar, o refletir diante de uma determinada situação. A história individual é constituída a partir da história de outro; o sujeito é singular a partir das relações com o outro. Mas é preciso ter clareza de que "[...] o plano intersubjetivo não é o plano 'do outro', mas o da relação do sujeito com o outro" (GÓES, 2000, p. 24). É por isso que "[...] todas as ações adquirem múltiplos significados, múltiplos sentidos, e

Movimento, Porto Alegre, v.13, n. 02, p.13-35, maio/agosto de 2007. 
tornam-se práticas significativas, dependendo das posições e dos modos de participação dos sujeitos nas relações" (SMOLKA, 2000, p. 31).

Neste estudo, percebemos esses múltiplos significados e sentidos nos discursos das professoras de Educação Física da escola. Ao internalizar os modos de ação de um determinado momento histórico, vão constituindo um referencial "seu", vão constituindose professoras, vão significando diferentes ações.

Na multiplicidade de sentidos, reside a possibilidade de uma significação de novos conceitos para com os objetivos da Educação Física, desde que estes sejam bem explicitados. Através da produção de sentidos, podemos vislumbrar novas concepções que, em nosso entendimento, podem significar a atuação das professoras na escola.

Através desses referenciais direcionamos este estudo, dialogando com as informações obtidas nas entrevistas realizadas com as professoras. Estabelecemos até aqui, à guisa de contextualização da realidade sobre a qual se assenta a temática, a explicitação de alguns conceitos para compreender a constituição das professoras. Isso não quer dizer que tais concepções não serão retomadas e sim que essas encontrar-se-ão permeadas ao longo deste estudo, nas "idas e vindas" do diálogo estabelecido com as falas das professoras, com os conceitos, sentidos e significados das obras consultadas e com a compreensão destes professores-pesquisadores.

\section{A EDUCAÇÃO FÍSICA NA ESCOLA: "COMO FORAM NOSSAS AULAS?"}

Nas trajetórias das professoras, procuramos identificar como essas foram construindo sua identidade, que é pessoal, acadêmica e profissional, já que não há como separar a pessoa da professora, ou vice-versa.

O professor é a pessoa. E uma parte importante da pessoa é o professor (NIAS, 1991). Urge por isso (re)encontrar espaços de interacção entre as dimensões pessoais e profissionais, permitindo aos professores apropriar-se dos seus processos de formação e dar-lhes sentido no quadro das suas histórias de vida (NÓVOA, 1997, p. 25).

Movimento, Porto Alegre, v.13, n. 02, p.13-35, maio/agosto de 2007. 
Nas experiências/vivências das professoras enquanto alunas, optamos por fazer um recorte acerca das aulas de Educação Física na tentativa de compreender os sentidos e significados de sua atuação na escola.

Nas falas das professoras, encontramos elementos que nos permitem interpretar, a partir de sua compreensão, como eram suas aulas enquanto alunas do ensino fundamental e médio. Seria muita pretensão colocarmonos no lugar do outro, já que este nunca está no lugar que o colocamos. O que fazemos neste texto é interpretar, a partir de "nossa" compreensão, o que julgamos "ser" as falas das professoras. Da mesma forma, estabelecemos um diálogo com a teoria, buscando, em diferentes obras, subsídios para compreender essas falas, situando-as no tempo, contextualizando-as, apropriando-nos de alguns conceitos que nos permitem lançar um olhar hermenêutico constituído na fusão dos horizontes do intérprete (neste caso, "nós") e das obras (falas das professoras) (PALMER, 1986).

Com relação às aulas no Ensino Fundamental, ${ }^{2}$ a Professora A conta-nos, que desde a $1^{\mathrm{a}}$ até a $7^{\mathrm{a}}$ série, não havia um professor formado para ministrar aulas de Educação Física, as aulas eram ministradas por professores de outras áreas, reproduzindo uma mesma prática da $1^{\mathrm{a}}$ a $7^{\mathrm{a}}$ série, produzindo uma cultura na escola de "jogar caçador". Revela a professora que, a partir da $8^{\mathrm{a}}$ série, começou a trabalhar na escola um professor de Educação Física formado, “[...] mas ele também não era muito... não tinha muita atividade, que eu lembro mais, ele fazia era atletismo, corrida, salto, isso aí ele dava, mas jogo, assim vôlei, isso aí eu fui aprender mesmo no $2^{\circ}$ Grau". Constatamos, a partir dos enunciados da Professora A, como esta apropriou-se dos significados de sua escolaridade, estabelecendo um referencial acerca da Educação Física, construindo um imaginário no que se refere a esta disciplina.

Situada em um outro momento histórico, ${ }^{3}$ a Professora B revela que, no Ensino Fundamental, da $1^{\mathrm{a}}$ a $3^{\mathrm{a}}$ série, era a professora regente que ministrava aulas de Educação Física: “[...] nós tínhamos

${ }^{2}$ Nova denominação para o $1^{\circ}$ Grau. Situando no tempo, estes fatos ocorreram por volta dos anos 1960.

${ }_{3}^{3}$ Mais precisamente na década de 1980.

Movimento, Porto Alegre, v.13, n. 02, p.13-35, maio/agosto de 2007. 
atividades mais de recreação, brincadeiras, pequenos jogos, cada macaco no seu galho [...]". A partir da $4^{\mathrm{a}}$ série, prossegue a professora B:

[...] o professor começou com iniciação esportiva, que eu me lembro, assim, principalmente o vôlei, foi trabalhado; $5^{\text {a }}$ série eu tive uma experiência com atletismo, as aulas eram bem numa linha... bem militar, no sentido de ordem de fila sempre antes da aula, cobrir... aí o atletismo foi trabalhado um pouco, handebol também e é mais ou menos o que eu lembro é isso. Durante as outras séries $\left(6^{\mathrm{a}}\right.$, $7^{\mathrm{a}}$ e $8^{\mathrm{a}}$ ) foi mais em função do handebol e do vôlei, alguma coisa de vôlei, mas mais voltada ao handebol.

Em suas referências escolares, a Professora B também aponta para uma Educação Física voltada ao esporte, sem uma diferenciação nos conteúdos trabalhados em cada série.

Nas referências quanto à sua escolarização, enquanto alunas do Ensino Fundamental de escolas públicas, aparecem elementos significados em cada momento histórico, formando conceitos, produzindo sentidos para as alunas, a partir da prática do esporte na escola. Com base nos interesses e normas da instituição e/ou próprios, os professores selecionam, de acordo com o tempo vivido, não só os métodos de ensino, como também os conteúdos a serem trabalhados pela disciplina na escola; nestes casos, o esporte.

Na passagem para o Ensino Médio, houve uma melhora significativa, segundo a Professora A, pois as aulas de Educação Física eram em turno inverso: "[...] eram professores especializados, era bem diferente". O que nos chamou a atenção na mudança a que se refere a Professora A diz respeito a uma nova especialização, passando do atletismo para o vôlei e a ginástica: "[...] que eu lembro mais era vôlei e mais ginástica". Ao questioná-la sobre a participação em torneios, ela revela: "[...] eu nunca me envolvi muito como atleta... eu tinha muita dificuldade até pra jogar... faltou incentivo, sei lá, motivação por parte dos professores". Sem a pretensão de emitir juízos ou, mesmo, julgar os professores e/ou até os alunos que viviam naquele contexto, percebemos que o trabalho diferente, exposto pela professora, deve-se ao fato de um trabalho melhor estruturado (materiais, espaço físico, professores especializados, etc.), tendo em

Movimento, Porto Alegre, v.13, n. 02, p.13-35, maio/agosto de 2007. 


\title{
20 Antifos Originais
}

Luciano de Almeida, et al.

vista tratar-se de uma escola particular. A Professora A fala, a partir de seus referenciais, do seu imaginário a respeito da Educação Física, que vem sendo construído em suas experiências escolares.

Continuando a estudar em escola pública, a Professora B não participava das aulas de Educação Física. Essas aulas também eram em turno inverso. Desde o $1^{\circ}$ ano tinha atestado médico "pra não participar das aulas". Apesar de não trabalhar no turno inverso, alega que "não gostava das aulas, não gostava da forma como eram dadas as aulas, então eu preferia não participar". Como eram dadas essas aulas?

\begin{abstract}
As aulas eram em cima de jogos, era largada uma bola pra jogar, jogavam aqueles que tinham mais habilidade, os outros ficavam sentados olhando e, então, por isso eu não gostava, não era muito habilidosa, então não participava, no Ensino Médio a prioridade era o vôlei, com a mesma professora da $8^{\mathrm{a}}$ série. (PROFESSORA B)
\end{abstract}

Apesar de não participar das aulas de Educação Física na escola, a Professora B “[...] praticava ginástica, ginástica de academia, fazia ballet, jazz, natação, fora das aulas eu tinha uma vida bastante ativa em relação à atividade física".

Refletem-se, em suas falas, "como imagens em um espelho", interesses situados em cada momento histórico. A percepção que temos frente a essas falas é diferente da dos professores que ministravam essas aulas nos respectivos momentos históricos, bem como a percepção dos alunos que viviam aquele momento de maneira diferenciada, pelas exigências do tempo vivido.

Na década de 60-70, em que a Professora A era aluna do Ensino Fundamental e Médio, a Educação Física constituía-se, enquanto área do saber, sob forte influência do esporte. Era entendida como um prolongamento da instituição esportiva, assumindo os códigos e normas dessa instituição. Também nessa década, politicamente, tais códigos e normas " [...] predominam no sistema educacional brasileiro, sob a égide da ditadura militar, do projeto 'Brasil-Grande'. É a época dos objetivos operacionais, do primado do planejamento, da

${ }^{4}$ Expressão utilizada por Fontana (2003) em sua obra Como nos tornamos professoras?.

Novimento, Porto Alegre, v.13, n. 02, p.13-35, maio/agosto de 2007. 
tecnologia do ensino" (BRACHT, 1997, p. 23). Sob as influências do contexto histórico-cultural, determinados pelo Estado e suas reformas políticas, a Professora A sente os reflexos dos objetivos da época, sendo marcada pela cultura que se estabelecia. Praticamente as aulas de Educação Física eram reduzidas ao esporte de rendimento.

Já na década de 80-90, na chamada “crise” da Educação Física, em que os pressupostos e o próprio discurso acerca desta disciplina estavam sendo rediscutidos na comunidade acadêmica, no intuito de denunciar os propósitos do esporte de rendimento, refletir sobre tendências mais amplas para a formação "integral do ser humano" e evitar reducionismos ao simples treinamento. Acreditamos que essas discussões se voltaram para os meios acadêmicos, chegando em pequena escala aos meios escolares, o que confirma a tese já esboçada por autores como Elenor Kunz e Valter Bracht. Essa afirmação é baseada, também, na própria fala da Professora B quando esta revela que suas aulas (enquanto aluna do Ensino Fundamental) "eram em cima de jogos", aulas essas em que alguns jogavam e outros ficavam sentados, olhando. Essas ações marcam/ marcaram sua trajetória.

As professoras A e B são marcadas pelas suas trajetórias escolares, significando, suas ações e as ações de seus professores enquanto alunas. Assim vão construindo "seus" referenciais acerca da Educação Física. Cabe destacar que essas marcas ficam mais evidentes no decorrer deste trabalho, quando duas histórias se revelam. A professora à qual se refere a Professora $\mathrm{B}$ na $8^{\mathrm{a}}$ série $\mathrm{e}$ no Ensino Médio era a Professora A.

\section{A ESCOLHA DA PROFISSÃO: UM CAMINHO A PERCORRER...}

A escolha da profissão não é uma tarefa fácil, é uma opção que se faz retomando os vários dias vividos durante nossa constituição, enquanto sujeitos históricos e culturais, a partir dos encontros e desencontros com nossos interesses e intenções e, também, com os interesses e intenções de outros, o que medeia uma tomada de decisão. Isso fortalece uma tese já esboçada de que a escolha dos professores não é fruto apenas de uma opção individual, "[...] mas de um conjunto de fatores externos que, aliados às condições subjetivas do sujeito,

Movimento, Porto Alegre, v.13, n. 02, p.13-35, maio/agosto de 2007. 


\section{Antifor Originais}

Luciano de Almeida, et al.

constituem as circunstâncias de vida, nas quais se desenrolam os momentos de escolha" (BORGES, 2001, p. 89).

Quando questionada acerca da escolha da profissão, a Professora A refere-se a um "dom" que possuía. Quando esta se refere a um "dom", o interpretamos como uma escolha já definida por "eleição divina" ou "natural", mesmo antes de seu nascimento. ${ }^{5}$ Revela-se, também, o imaginário que construiu acerca da disciplina na escola, durante suas experiências enquanto aluna, uma Educação Educação Física voltada somente para a "prática" de atividades esportivas, em que não havia discussão, nem "teoria", um imaginário de que "quem sabe fazer também pode ensinar".

Na perspectiva da Professora B, o que a levou a escolher o curso foram as suas relações com a disciplina na escola, em especial no Ensino Médio, quando esta não participava das aulas. O desejo de significar novas ações para a Educação Física na escola reflete a possibilidade de contribuir para constituir um novo referencial para a disciplina a partir de uma prática diferente. Nas interações da Professora B com os outros, especialmente com sua amiga, concretiza-se a escolha pelo curso e a "certeza" de "ter algo de diferente" para atender aos seus interesses, desejos e expectativas e a intenção de atribuir outros significados e sentidos à Educação Física.

\section{5 À PROCURA DE "ALGO DIFERENTE” NA EDUCAÇÃO FÍSICA}

Depois da escolha, as professoras viveram a expectativa de atender suas necessidades e/ou interesses. Encontram outros desejos, expectativas e/ou interesses de outras pessoas que dividiram com elas o espaço educacional da universidade. Nas diferentes relações que serão estabelecidas com a instituição - professores, alunos, amigos -, dar-se-á o encontro com outras concepções, outras escolhas, outros olhares, que, de alguma forma vão fazer parte desse

${ }^{5}$ Esclarecemos que, de maneira alguma, isso deve ser considerada uma crítica à posição da professora. Ficamos à vontade para refletir sobre tal posição, já que acreditamos ser nas interações com o outro que nos constituímos. Inspirados na hermenêutica de Paul Ricoeur, acreditamos que "criticar não é 'falar mal', mas apontar acertos e estabelecer limites. Nenhuma teorização consegue recobrir toda a complexidade, todas as incertezas e contradições da realidade humana" (apud BETTI, 1998, p. 12).

Movimento, Porto Alegre, v.13, n. 02, p.13-35, maio/agosto de 2007. 
complexo processo de constituição do aluno-professor. Em diferentes momentos na história, dois cursos, duas instituições.

Na década de 70, quando prestou o vestibular para iniciar no curso escolhido, a Professora A revela que, além da prova teórica, havia também prova prática: "[...] corrida, salto, que eu lembro foi isso, nada assim de jogo, nada... mais era teste de resistência". "Responsáveis pela formação dos futuros profissionais de Educação Física, as instituições de ensino superior superdimensionavam o saber técnico e as capacidades físicas em seus currículos, utilizando-os inclusive como critério seletivo para ingresso em seus cursos" (FENSTERSEIFER, 2001, p. 33). Situados no tempo, percebemos que o objetivo maior da Educação Física era formar atletas, professores hábeis, com uma boa condição física, que soubessem fazer para saber demonstrar. Esta afirmação é constatada pela própria fala da professora, quando se refere às expectativas que tinha com relação ao curso:

[...] eu não sei... eu tinha a impressão que eles iam ensinar mais a dar aula, a tu ser professor mesmo... mas, nesse curso que eu fiz, eles ensinavam a gente a ser atleta. Essa foi uma das decepções que eu tive; eles não ensinavam tu ter mais didática; passou assim muito superficial. Essa expectativa, até hoje eu sinto falta, porque eu achei que eles iam ensinar mais a gente a ser professor, a ensinar os alunos, a gostar de esporte. Isso eu não senti nada. (PROFESSORA A)

Na formação da Professora A, constatam-se as deficiências e a imposição de limites na futura intervenção da aluna-professora. ${ }^{6}$ A Professora faz referência à metodologia das aulas voltadas para o saber-fazer: "[...] é verdade, tu tinha que saber... Eu tive sorte que na natação eu fui super bem, passei direto, porque tinha colegas que ficaram nove anos fazendo natação e não conseguiam sair do curso". Da mesma forma que critica as aulas que teve na Universidade, foi "marcada" por uma professora:

\footnotetext{
${ }^{6}$ Chamamos a atenção para os objetivos de uma Educação Física voltada para a aptidão física e formação de atletas, de acordo com os interesses e/ou necessidades daquela época. Essa compreensão é situada no presente, a partir de significados e sentidos outros para a Educação Física, assim como os limites a que nos referimos e a que se refere a professora, dizem respeito às novas concepções do que é/foi/pode vir a ser a Educação Física.

Movimento, Porto Alegre, v.13, n. 02, p.13-35, maio/agosto de 2007.
} 


\section{Astigos Origimais}

[...] ah eu... que me chamou, até hoje me marcou muito, não sei se é porque eu gostava da matéria que era ginástica geral... naquela época a gente chamava ginástica geral, era ginástica geral, daí entrava rítmica, entrava ginástica de solo. Então pra mim foi a que eu mais amei, porque eu só tirava 90, 100, até na hora de demonstrar ela sempre me chamava. Até hoje o que eu mais gosto é do alongamento, da ginástica. Ela ensinou muito bem. Ela dava os planos de aula perfeitos; até meu estágio, quando eu fiz, eu escolhi a ginástica de tanto que eu gostava. (PROFESSORA A)

As referências que vão constituindo a aluna-professora ficam explicitadas no seu discurso, sob forte influência da professora de ginástica produzindo "marcas" em sua formação.

Mais uma vez fazemos referência ao momento histórico vivido pela Professora B, que é de fundamental importância, em que os discursos e pressupostos acerca da Educação Física estavam sendo discutidos, principalmente no meio acadêmico. Sob essas influências, há uma preocupação com a formação dos futuros professores, mudança nos currículos, novos conceitos, novos significados para as exigências de uma Educação Física preocupada com as dimensões sociais, históricas e culturais.

Quando iniciou sua caminhada acadêmica, a Professora B fez referência a uma disciplina e a um professor que reafirmaram sua escolha. Encontrou o "algo diferente" a que se referia, quando solicitada a falar acerca de sua escolha. Percebemos também, em sua fala, que manifestava tendências de trabalhar com uma Educação Física mais voltada para a saúde. Demonstra ainda muita aversão ao esporte, pelas experiências que teve durante sua formação escolar. Em seu curso, trabalhava-se bastante a parte esportiva; porém, com outros significados:

[...] tinha uma formação mais humanista, te dava uma visão diferente daquilo... treinamento dentro da aula de Educação Física, onde alguns jogavam e os outros sentavam e ficavam olhando, te dava uma visão bem diferente onde todos teriam oportunidade de participar da aula. (PROFESSORA B).

Movimento, Porto Alegre, v.13, n. 02, p.13-35, maio/agosto de 2007. 
A aversão ao esporte, aos poucos, vai cedendo lugar à aceitação, ao entendimento, a novos conceitos de esporte com outros sentidos.

Na fala das professoras, percebemos a produção de significados e sentidos determinados pela instituição, curso, professores, em cada momento histórico. De um lado, uma formação voltada à aptidão física e à formação de atletas; de outro, a preocupação com a formação de um "ser humano integral", não mais só treinamento. O que chama a atenção em seus depoimentos é a referência a uma professora e a um professor de ginástica que marcaram suas trajetórias acadêmicas.

\section{INGRESSANDO NO UNIVERSO PROFISSIONAL: DIFICULDADES E EXPECTATIVAS}

A entrada no universo de trabalho, em nosso caso, a escola, é um caminho repleto de dúvidas, expectativas e incertezas. Nossas experiências anteriores vividas na escola, como alunos, e na universidade, como acadêmicos, começam a produzir novas relações, que passam de alunoacadêmico a professor. Afinal, na universidade, na maioria das vezes, trabalhamos com nossos colegas e, na escola, trabalhamos com os alunos, sujeitos diferençados com interesses, desejos e anseios também diferentes daqueles a que estamos acostumados a enfrentar.

As duas professoras contam que seu ingresso na escola ocorreu antes da conclusão do curso de Educação Física. Quanto às dificuldades na escola:

[...] tive várias dificuldades porque a gente tinha pouco material, pouco espaço aqui na escola, não tinha o ginásio coberto, só tinha uma quadra. Tinha eu e mais dois professores, então tinha que revezar, um usava a quadra, o outro tinha que ir no gramado, outro ficava na sala de aula, então tinha dificuldades. Pra começar eu tinha pouca experiência, claro que isso aí é óbvio quando tu começa tu não tem experiência e, além de tudo, tinha pouco material. Eu comecei dar os educativos, os fundamentos, eu mesmo fui procurando... a gente foi pesquisando e foi tentando botar na prática, mas era tudo experiência, então os alunos "tavam" sendo cobaias. Eu "tava" começando. (PROFESSORA A)

Movimento, Porto Alegre, v.13, n. 02, p.13-35, maio/agosto de 2007. 


\title{
26 Astifor Originais
}

A Professora B revela que, quando iniciou:

\begin{abstract}
a maior dificuldade que eu encontrei foi... conseguir realizar nas minhas aulas, nas aulas que eu planejava, alguma coisa de diferente daquilo que eu tinha vivido enquanto aluna de Educação Física [na escola]. Quanto à relação de materiais, era precária mas eu acho que consegui assim fazer um trabalho, não digo excelente, mas razoável. Claro que os alunos também têm uma resistência muito grande a algo diferente, a alguma mudança e, na escola que eu trabalhava, o professor que trabalhava antes, trabalhava muito voltado ao esporte e ao treinamento, então foi difícil chegar com uma proposta diferente, porque os alunos também ofereceram uma resistência muito grande.
\end{abstract}

A inserção das acadêmicas-professoras no universo profissional também foi cercada de expectativas e de angústias, ocasionadas pela falta de experiência na nova relação que começava a se estabelecer. A realidade encontrada pelas professoras na escola é diferente daquela conhecida na universidade. De um lado, a formação voltada ao saber-fazer e ao treinamento limita a Professora A à aplicação dos fundamentos técnico-instrumentais, reproduzindo o que havia aprendido na universidade, mediante a adaptação de seus conhecimentos à realidade da escola, dentro dos princípios do esporte de rendimento. De outro, a formação de um "ser humano integral", com novos conceitos, sentidos e significados para a Educação Física; porém, mediante um saber descontextualizado, barrado na oposição dos alunos à implementação de uma nova proposta, limitada por uma formação estabelecida na relação dicotômica teoria-prática (PROFESSORA B).

\footnotetext{
Ao longo de sua história de vida pessoal e escolar, supõe-se que o futuro professor interioriza um certo número de conhecimentos, de competências, de crenças, de valores, etc., os quais estruturam a sua personalidade e suas relações com os outros (especialmente com as crianças) e são reatualizados, de maneira não reflexiva mas com grande convicção, na prática do ofício. Nessa perspectiva, os saberes experienciais do professor de profissão, longe de serem baseados unicamente no trabalho em sala de aula, decorreriam em grande parte de preconcepções
}

Movimento, Porto Alegre, v.13, n. 02, p.13-35, maio/agosto de 2007. 
do ensino e da aprendizagem herdadas da história escolar (TARDIF, 2002, p. 72).

Até aqui, com uma narrativa permeada de diálogos, entrevistas, reflexões, conceitos, significados, sentidos e apropriações, percorremos os caminhos trilhados pelas professoras, desde a sua passagem pela escola, enquanto alunas, pela universidade, enquanto acadêmicas do curso de Educação Física, chegando à sua entrada na escola agora como professoras. Nos diálogos estabelecidos com as alunas-acadêmicas-professoras, revelam-se fatos de sua vida pessoal e profissional, pois, repetindo a afirmação que havíamos feito anteriormente, mais uma vez recorremos a Nóvoa (1997), quando este considera que não há como separar o professor da pessoa e a pessoa do professor. Nas diferentes relações que estabeleceram com o outro (social), a construção de uma identidade, de acordo com o autor:

[...] não é um dado adquirido, não é uma propriedade, não é um produto. A identidade é um lugar de lutas e conflitos, é um espaço de construção de maneiras de ser e de estar na profissão. Por isso, é mais adequado falar em um processo identitário, realçando a mescla dinâmica que caracteriza a maneira como cada um se sente e se diz professor. A construção passa sempre por um processo complexo graças ao qual cada um se apropria de um sentido da sua história pessoal e profissional. É um processo que necessita de tempo. Um tempo para refazer identidades, para acomodar inovações, para assimilar mudanças. (NÓVOA, 1995, p. 16)

Acrescentamos a essa afirmação, que nos apropriamos dos sentidos produzidos em nossas histórias pessoais e profissionais em constantes interações com o meio físico e social, com a cultura e com a história.

Com o passar do tempo, "refazemos identidades", "acomodamos inovações", "assimilamos mudanças". Recorremos à história através das falas das professoras que nos contaram suas trajetórias desde a escola até a entrada no universo profissional. Para refletirmos sobre o presente das professoras, enquanto profissionais de Educação Física

Movimento, Porto Alegre, v.13, n. 02, p.13-35, maio/agosto de 2007. 


\title{
28 ArtigorOriginais
}

Luciano de Almeida, et al.

da mesma escola, destacamos dois trechos das entrevistas realizadas com elas e que demandam compreensão. Aparecem nesses fragmentos das entrevistas as dificuldades do "ser professor" na realidade da escola:

\begin{abstract}
Nós não chegávamos e só dávamos o jogo. Agora não, eles não querem mais saber disso [educativos]. Então tu já chega e tem que colocar "eles jogar”, tu dá um aquecimento, alonga, faz alguma coisa e já coloca "eles jogar". Eu tô fazendo assim. (PROFESSORA A).

É uma coisa que está presente no dia-a-dia do professor de Educação Física: a questão do fazer por fazer. Muitas vezes eu paro e fico pensando até que ponto as minhas aulas estão sendo diferentes das aulas que eu tive. Apesar de tentar fazer alguma coisa diferente, de tentar mudar, de ter uma consciência voltada... à transformação da Educação Física, muitas vezes eu ainda acho que as minhas aulas estão sendo iguais àquelas que eu tive enquanto aluna na escola. (PROFESSORA B)
\end{abstract}

Ao analisarmos as falas das professoras, fomos percebendo como essas se constituem profissionais de Educação Física. Através das interações com o outro, as professoras vão construindo seus referenciais. Refletindo sobre o presente, revelam as dificuldades do ser professor no contexto escolar. Apesar de serem formadas em diferentes instituições e em distintos momentos históricos, em explicar que suas práticas sejam tão semelhantes, caracterizadas pela prática de atividades esportivas? Para essa questão, entretanto, não cabe a simples afirmação de que as professoras se acomodaram frente às dificuldades encontradas na realidade da escola em que atuam.

Acreditamos que, sem um aprofundamento teórico, sem uma análise das práticas subjacentes das professoras e da realidade em que se inserem, estaríamos simplificando essas relações complexas que acontecem no contexto escolar. Dentre os muitos caminhos possíveis para interpretar essa questão, optamos por reconhecer algo como uma "cultura escolar" (VAGO, 2003), que embora não seja alheia ao que se passa no contexto social mais amplo, possui uma certa autonomia capaz de aos poucos absorver os que nela se

Movimento, Porto Alegre, v.13, n. 02, p.13-35, maio/agosto de 2007. 
inserem de maneira quase imperceptível. Acreditamos que sem adentrar neste universo e interagir com ele, pouco se avançará em termos de compreensão e intervenção.

\section{CULTURA ESCOLAR, ESCOLA E EDUCAÇÃO FÍSICA}

Regulemos o foco de nossas "lentes", agora, sobre a questão da cultura escolar, a qual, muitas vezes, nos induz a reproduzir o que por momentos rejeitamos, gerando um acomodamento que tende à naturalização. Apesar de todos nós sermos formados em diferentes momentos históricos e em diferentes instituições, em que os discursos acerca da Educação Física são diferentes, como explicar que nossas práticas possam tornar-se tão semelhantes? Uma boa tentativa para pensarmos tal questão seria relacioná-las com a estrutura que a escola nos oferece e o que deseja de nós. Pensemos na escola como lugar de objetificação de valores e normas que ultrapassam a subjetividade de seus componentes, uma espécie de "cultura própria"7 (VAGO, 2003).

Faz-se necessário porém que embora possamos reconhecer que a escola possui uma "cultura própria", devemos tomar cuidado para não naturalizá-la, ${ }^{8}$ buscando compreender esse espaço próprio da instituição escolar com suas regras, normas, rituais, costumes, inércias, etc.

Cabe lembrar que vivenciando espaços e tempos distintos, realizamos a produção, reprodução e transformação da cultura de determinado grupo social em que nos inserimos e, conseqüentemente, significamos nossas ações com referência em alguém quem um dia nos espelhamos. São as construções histórico-culturais de determinados grupos que nos permitem internalizar/tornar próprias as ações que estabelecemos a partir das inter-relações com o outro. Assim, ao estarmos em contato com a cultura de determinados grupos, vamos reconhecendo suas peculiaridades, avaliando-a a partir de nossos referenciais e confrontando significados e sentidos que esta nos apresenta.

\footnotetext{
${ }^{7}$ Manteremos esta expressão entre aspas como forma de chamar a atenção para sua ambigüidade, pois, não reconhecemos sólidos muros a separar a "cultura escolar" da cultura de uma determinada sociedade, apenas reconhecemos nesta expressão uma forma de chamar a atenção para a especificidade deste espaço institucional.

${ }^{8}$ Entendemos que o termo "naturalização" aqui utilizado deve estar associado à prática inconsciente de conceber a realidade escolar, ou seja, à reprodução inconsciente da cultura sem uma análise reflexiva.
}

Movimento, Porto Alegre, v.13, n. 02, p.13-35, maio/agosto de 2007. 


\section{Astifor Originais}

A trama complexa das relações entre sujeitos mediados pelas condições reais de trabalho no contexto escolar levou-nos a interpretar a escola como lugar, tempo e espaço de produção de uma "cultura própria", a cultura escolar (VAGO, 2003), entendida aqui como um:

[...] conjunto de aspectos institucionalizados inclusive práticas e condutas, modos de vida, hábitos e rituais - a história cotidiana do fazer escolar - objetos materiais - função, utilização, distribuição no espaço, materialidade física, simbologia, introdução, transformação, desaparecimento [...] - e modos de pensar, assim como significados e idéias compartilhadas. Alguém dirá: tudo. Sim, está certo, a cultura escolar é toda a vida escolar: feitos e idéias, mentes e corpos, objetos e condutas, modos de pensar, dizer e fazer (VIÑAO FRAGO apud VAGO, 2003, p. 202) (tradução livre).

O contexto escolar - como uma espécie de "roda viva" - foi absorvendo a entrada dos profissionais em seu interior, limitando-os a percorrer os caminhos trilhados pelos profissionais que os antecederam, levando-os a adaptarem-se às práticas já postas nesse espaço educacional. Entendemos aqui o termo "adaptação" como um "moldar-se" às condições reais de trabalho, processo este que se dá num movimento sub-reptício, quase imperceptível.

Desde o seu surgimento, a escola apresenta-se como:

[...] lugar, tempo e recursos destinados às aprendizagens em interação dialogal dos nelas interessados com Outro socialmente qualificado, para compartilharem do entendimento, da organização e da condução dos processos formais do aprender mediado pelo ensinar. E, quanto mais complexa, isto é, plural e diferençada, se apresente a sociedade, mais se exigem as aprendizagens sob a forma escolar, distinta das modalidades próprias de outros contextos sociais e âmbitos lingüísticos (MARQUES, 2000, p. 87).

Nossa investigação demonstra que, na escola pesquisada, as professoras, apesar de alguns esforços, não estão conseguindo articular uma prática pedagógica que satisfaça suas próprias expectativas em

Movimento, Porto Alegre, v.13, n. 02, p.13-35, maio/agosto de 2007. 
relação ao componente curricular que ministram e, por isso, acabam caindo na "rotina" de uma "cultura escolar do esporte" que, por um lado, proporciona aos alunos momentos de lazer, de um prazer imediato. ${ }^{9}$ Por outro, compromete a sua aprendizagem, limitando-os a "usufruírem do esporte", nos limites de uma compreensão prévia, tornando-os incapazes de auxiliar na (re)significação da Educação Física enquanto área do saber, além de espaço de pesquisa, de reflexão e de produção do conhecimento. Enquanto esse espaço permanecer fechado, continuaremos a pegar "carona" com o esporte.

O que aprendemos também é que não basta apenas analisarmos o tempo-espaço da formação dos professores e a maneira como produzem sua prática, como também não podemos naturalizar essa prática aceitando, acomodando a "cultura escolar" em que estamos inseridos. Faz-se necessário buscar uma formação continuada analisando esta realidade, para refleti-la e mudá-la, atribuindo-lhe novos sentidos. Concordando com Ezpeleta e Rockwell (1989, p. 22), “[...] compreendemos que é possível reconstruir o que ocorre diariamente em qualquer 'parte' da realidade social, mesmo nos lugares privilegiados pelas visões legitimadoras". A escola, como "parte" da realidade social, nunca é realidade dada de vez, é espaço e tempo destinado à reconstrução do saber que marca e é marcada pelos sujeitos que por ela passam.

A Educação Física, da mesma forma, como parte integrante dessa instituição, juntamente com as demais disciplinas, precisa ser repensada e reconhecida como um espaço aberto de pesquisa, reflexão e produção do conhecimento. Uma das alternativas possíveis para se chegar a esse fim de transformação da Educação Física está na perspectiva metodológica da pesquisa-ação, que pode contribuir para a (re)significação da Educação Física no contexto escolar, além de auxiliar no processo de formação contínua dos professores, já que vincula o "conhecimento da realidade, da própria prática, com a ação" (BRACHT et al., 2003, p. 71).

\footnotetext{
9 Podemos chamar esse prazer imediato ou "gozo imediato" de "falso hedonismo", uma vez que não leva em conta o longo prazo, no qual se efetivam os objetivos educacionais. Esse quadro compromete a questão ensino-aprendizagem a qual consideramos tarefa primordial da instituição escolar.

Movimento, Porto Alegre, v.13, n. 02, p.13-35, maio/agosto de 2007.
} 


\section{Astifor Originais}

Luciano de Almeida, et al.

Não queremos fazer afirmações categóricas de que esse é o único caminho possível para se chegar a uma mudança significativa nas práticas dos profissionais da educação, mas acreditamos que o estreito vínculo entre teoria e prática, materializado na relação entre a formação inicial e a vida nas escolas,$^{10}$ pode auxiliar no processo de constituição desses profissionais, contribuindo assim para que estes possam atuar refletindo sobre o seu fazer diário, (re)significando, transformando, interpretando e compreendendo as diferentes situações que se apresentam em seu contexto de trabalho.

\section{CONSIDERAÇÕES FINAIS}

No decorrer desta pesquisa, percebemos que o termo "naturalização" não era o mais apropriado para compreender a prática das professoras. Este termo refere-se a uma prática inconsciente de tomar um fenômeno não-natural por natural. Exemplificando essa afirmação, podemos perceber que as professoras elaboram argumentos condizentes com o papel da Educação Física no contexto escolar; porém, apesar de algumas tentativas, não conseguem afirmar praticamente suas crenças na intervenção, sentindo-se impotentes frente à realidade escolar. Um dos condicionantes evidenciados é a falta de vínculo entre sua formação inicial e a vida nas escolas, fenômeno que demanda a compreensão de sua complexidade, a qual envolve questões como a "cultura escolar", as especificidades de cada escola em particular, a história da Educação Física enquanto componente curricular, entre outras. Sem levar isso em consideração continuaremos a reproduzir essas mesmas práticas sem refletir sobre elas, e, de forma simplista, culpando os professores e esperando de sua ação heróica a redenção da Educação Física.

As incertezas desta pesquisa foram reveladas desde o seu início, quando não conseguimos constituir o grupo de estudos e construir uma proposta coletiva para intervir na realidade da escola. Na mudança de estratégia, foram apresentadas duas experiências que, embora distintas, convergem em uma prática semelhante. A partir da análise da trajetória

\footnotetext{
${ }^{10}$ Molina Neto e Molina defendem essa relação, ao afirmarem que o professor é um "[...] ser não-fragmentado que age relacionando sua formação com sua trajetória docente, com sua prática cotidiana, com o conhecimento construído na experiência, e com as crenças que elabora durante sua existência" (2002, p. 61).

Movimento, Porto Alegre, v.13, n. 02, p.13-35, maio/agosto de 2007.
} 
e das ações de outros professores, podemos também, por extensão e analogia, identificar e compreender nossas próprias ações.

\begin{abstract}
Teachers of Physical Education: two stories, only one destiny

Abstract: This article exposes the trajectory of two Physical Education teachers of a public school in Santo Augusto (RS) who, despite being graduated in different historical moments, produce a similar practice, illustrated by the adoption of sports activities planed for themselves. This takes us to acknowledge the need for clarification of the details of school education, in particular Physical Education as well as better comprehend the scholarship culture. The experience in the search for the comprehension of pedagogic practice of other professional can offer us elements to justify our own actions in the school. Keywords: Education, primary and secondary. Professional practice. Physical Education. Cultural factors.
\end{abstract}

Maestras de Educación Física: dos historias,
un solo destino
Resumen: Este artículo descubre la trayectoria de
dos maestras de Educación Física de una escuela
de la red pública de San Augusto/RS que, más allá
de que se hayan graduado en distintos momentos
históricos, producen una práctica similar, caracteri-
zada por la adopción de actividades deportivas con
un fin en si mismas. Esa constatación nos lleva a
reconocer la necesidad de explicitar las particulari-
dades de la educación escolar, siendo mas especi-
fico de la Educación Física, bien como comprender
la Cultura Escolar. La experiencia de la búsqueda de
comprensión de las prácticas pedagógicas de otros
profesionales puede sumar elementos para que re-
pensemos nuestro propio accionar en la escuela.
Palabras-clave: Educación primaria y secundaria.
Practica profesional. Educación Física. Factores
culturales.

Movimento, Porto Alegre, v.13, n. 02, p.13-35, maio/agosto de 2007. 


\section{REFERÊNCIAS}

BETTI, Mauro. A janela de vidro: esporte, televisão e educação física. São Paulo: Papirus, 1998.

BORGES, Cecília Maria Ferreira. O professor de educação física e a construção do saber. 2. ed. Campinas, São Paulo: Papirus, 2001.

BRACHT, Valter. Educação física e aprendizagem social. 2. ed. Porto Alegre: Magister, 1997.

BRACHT, Valter et al. Pesquisa em ação: educação física na escola. Ijuí: UNIJUÍ, 2003.

EZPELETA, Justa; ROCKWELL, Elsie. Pesquisa participante. Tradução de Francisco Salatiel de Alencar Barbosa. 2. ed. São Paulo: Cortez/Autores Associados, 1989.

FENSTERSEIFER, Paulo Evaldo. A educação física na crise da modernidade. ljuí: Unijuí, 2001.

FONTANA, Roseli A. Cação. Como nos tornamos professoras? 2. ed. Belo Horizonte: Autêntica, 2003.

GIROUX, Henry. Teoria crítica e resistência em educação: para além das teorias de reprodução. Tradução de Ângela Maria B. Biaggio. Petrópolis: Vozes, 1986.

GÓES, Maria Cecília R. de. A natureza social do desenvolvimento psicológico. In: Pensamento e linguagem: estudos na perspectiva psicológica soviética. 3 . ed. Campinas: Cedes, 2000. p. 21-29 (Cadernos Cedes, 24).

KANT, Immanuel. Sobre a Pedagogia. Piracicaba: Editora Unimep, 1999.

MARQUES, Mario Osorio. A aprendizagem na mediação social do aprendido e da docência. 2. ed. ljuí: UNIJUí, 2000.

MOLINA NETO, Vicente; MOLINA, Rosane Kreusburg. Capacidade de escuta: questões para a formação docente em Educação Física. Movimento, Porto Alegre, v. 8, n. 1, p. 57-66, jan./abr. 2002.

NÓVOA, Antonio. Os professores e as histórias de vida. In: NÓVOA, Antonio (Org.). Vidas de professores. Porto: Porto Editora, 1995.

NÓVOA, Antonio. Formação de professores e profissão docente. In: NÓVOA, Antonio. Os professores e a sua formação. 3. ed. Lisboa: Dom Quixote, 1997. p. 13-33.

Movimento, Porto Alegre, v.13, n. 02, p.13-35, maio/agosto de 2007. 
PALMER, Richard E. Hermenêutica. Lisboa: Edições 70, 1986.

SMOLKA, Ana Luiza B. O (im)próprio e o (im)pertinente na apropriação das práticas sociais. In: Relações de ensino: análises na perspectiva histórico-cultural. Campinas: CEDES, 2000. p. 26-40 (Cadernos CEDES, 50).

TARDIF, Maurice. Saberes docentes e formação profissional. Petrópolis: Vozes, 2002.

VAGO, Tarcisio Mauro. A educação física na cultura escolar: discutindo caminhos para a intervenção e a pesquisa. In: A educação física no Brasil e na Argentina: identidade, desafios e perspectivas. Campinas: Autores Associados/Prosul, 2003. p. 197-221.

VIGOTSKI, Lev S. A formação social da mente: o desenvolvimento dos processos psicológicos superiores. São Paulo: Martins Fontes, 2002.

Movimento, Porto Alegre, v.13, n. 02, p.13-35, maio/agosto de 2007. 